\title{
The once-twice test for evaluation of the completely anesthetic digit
}

\author{
Steven J McCabe MD, Warren C Breidenbach MD, Hector A Herrand MD \\ Christine M Kleinert Institute for Hand and Microsurgery, Division of Plastic Surgery, Department of \\ Surgery, University of Louisville, Louisville, Kentucky, United States
}

\section{SJ McCabe, WC Breidenbach, HA Herrand. The once-twice test for evaluation of the completely anesthetic digit. Can J Plast Surg 1998;6(1):21-22.}

\begin{abstract}
A test to aid in the evaluation of the completely anesthetic digit - the once-twice test - is described. This rapid, easily performed clinical test can help identify patients with anesthesia of the digits of nonphysiological origin.
\end{abstract}

Key Words: Anesthesia, Sensibility, Two-point discrimination

\section{Le test once-twice pour l'évaluation d'un doigt complètement anesthésié}

RÉSUMÉ : On décrit ici un test utilisé pour évaluer le doigt complètement anesthésié, le test «once-twice». Ce test clinique, rapide et facile à exécuter, permet d'identifier les patients dont l'anesthésie digitale est d'origine non physiologique.

$\mathrm{C}$ linical assessment of digital sensibility relies on the perception and response of the patient to the stimulus applied by the examiner. When faced with a patient with a totally anesthetic digit and a questionable history of nerve compression or injury, the surgeon can use digital sweating or the wrinkle pattern of the skin following immersion in water as diagnostic evidence of lack of true nerve injury (1). The evaluation of these characteristics may be time-consuming and difficult to quantify, often leaving some ongoing uncertainty.

The authors have developed the once-twice test, a rapid, simple method to evaluate such patients. This test has been found useful in the authors' office practice. The once-twice test is a variant of the two-point discrimination and is, therefore, easily accepted by the patient. After ascertaining that no two-point discrimination is present in a digit, the once-twice test is indicated. Instead of touching the digit with one or two points (as in two-point discrimination), the patient is asked to determine whether the surgeon has touched the digit once or

Correspondence and reprints: Dr SJ McCabe, 225 Abraham Flexner Way, Suite 800, Louisville, Kentucky 40202, USA. Telephone 502-561-4238,

fax 502-561-4288, e-mail sjmccabe@iglou.com twice; the ability to do this does not rely on cutaneous sensibility (unknown to the patient). The time interval between the touches does not seem to be important; however, the authors use an interval of approximately $0.5 \mathrm{~s}$. If the patient responds once when the digit has been touched twice, the test is considered positive, and in the absence of some profound proximal problem (see below) the patient thus has evidence of a nonphysiological response. If the patient correctly responds twice for two touches and once for a single touch, a normal response is indicated and does not reveal the cause of lack of two-point discrimination.

It has been observed in the authors' office that patients who complain of anesthetic digits and have no two-point discrimination, with no clear history of nerve injury, may respond once when the digit is touched once or twice. In contrast, patients with documented nerve injury and true anesthesia of the digit retain their ability to discriminate one touch from two touches, probably through proprioceptive information. These finding have been found in the digits of patients with both digital nerves lacerated, lacerations of one or both major nerves at the wrist, during metacarpal block anesthesia and in severe diabetic neuropathy with total anesthesia of the digits. Patients with complete brachial plexus avulsion 
and a patient with a forearm level replantation in the early postoperative period do not have two-point discrimination and could not discriminate one touch from two touches. In patients with possible nerve compression disorders where no two-point discrimination is present, the once-twice test has helped differentiate severe compression from symptom magnification. The authors have not evaluated this test in central nervous system disorders.

The sensitivity and specificity of tests like the once-twice test are very difficult to calculate. The sensitivity or proportion of diseased patients (nonphysiological numbness) with a positive test relies on comparison with a gold standard, a comparison that is not possible in this situation. The specificity or proportion of normal tests in nondiseased people, which includes those with true numbness from nerve injury, seems to be very high except for the special conditions highlighted above. Perhaps these conditions will become more apparent with further clinical use of the test. The high specificity is important because a positive test will always be meaningful.

In the absence of severe proximal nerve injury, a positive once-twice test is a rapid method to make the surgeon aware of, and able to document, nonphysiological anesthesia of the digits.

\section{REFERENCE}

1. Lister G. The Hand Diagnosis and Indications. New York: Churchill Livingstone, 1984:112. 